\title{
Internet-of-Things for Smart Street Lighting System Using ESP8266 on Mesh Network
}

\author{
https://doi.org/10.3991/ijes.v9i2.22877 \\ Syifaul Fuada $\left({ }^{\otimes}\right)$ \\ Universitas Pendidikan Indonesia, Bandung, Indonesia \\ syifaulfuada@upi.edu \\ Trio Adiono \\ University Center of Excellence on Microelectronics, Bandung, Indonesia \\ Lindawani Siregar \\ Teaching Factory of Manufacturing Electronics, Batam, Indonesia
}

\begin{abstract}
IoT concept gained tremendous momentum in the technological advancements of this century because it has efficiently connected various devices wirelessly. The ESP8266 Wi-Fi serial transceiver module is one of the most used devices for IoT applications. In this paper, we design the IoT-based smart street lighting system using ESP8266 configured as a Mesh network. The ESP8266 was instructed (programmed) to control the light level, by producing a PWM signal, then it sends dimmer value and read the sensors data. Our system can be accessed wirelessly via a web server. The overall system was successful as a smart street lighting system on wireless Mesh environment. This research result also compared to the existing similar project in terms of the system complexity aspect.
\end{abstract}

Keywords-ESP8266, Internet-of-Things, Smart street light

\section{Introduction}

Smart street lighting system based on IoT is one of the solutions to minimize the energy consumption within the city as well as reduce the crews on site in maintenance processes [1]. IoT technology is being integrated into street lights that can be monitored remotely and provide notification to the admin user. The ESP8266 module is one solution to implement IoT. Moreover, the ESP8266 is a low-cost Wi-Fi technology compared to other IoT technologies (e.g., Zigbee, LoRa, Wi-Fi shield for Arduino, etc.) as shown in Table I. In previous work [2], we have reported the ESP8266 application for street lighting with a single node. The results confirmed that the node (LED module) could be controlled and monitored its status through an HTML-based web server.

The motivation of this paper is to add more nodes (street light) in our system. Hence, the link topology must be applied. The Mesh topology was chosen due to its 
simple network. In addition, the ESP8266 supports a feature to be configured as Mesh. Through this configuration, the street lights can communicate with each other wirelessly. Thus, the street light can be installed extensively with massive area coverage. If the node of street light blacks out, the other nodes (within range) will autonomously reconfigure the network. Therefore, the wireless connection of the street light is still be maintained.

Table 1. Cost Comparison of Existing IoT Module

\begin{tabular}{|l|c|}
\hline \multicolumn{1}{|c|}{ IoT Devices } & Price \\
\hline ESP8266 & $\$ 2.75-\$ 6.9$ \\
\hline Zigbee & $\$ 22$ \\
\hline LoRa & $\$ 40-\$ 70$ \\
\hline Wi-Fi Shield for Arduino & $\$ 84.95$ \\
\hline Huzzah WiFi Shield by Adafruit & $\$ 34.95$ \\
\hline Ethernet Shield for Arduino & $\$ 60$ \\
\hline
\end{tabular}

\section{Methods}

In this part, we describe the hardware and software parts of the smart street lighting system. The hardware can be divided into four blocks as illustrated in Fig. 1, i.e., 1) gateway system as coordinator, 2) node system as an end device, 3) modem and 4) web server as the primary user.

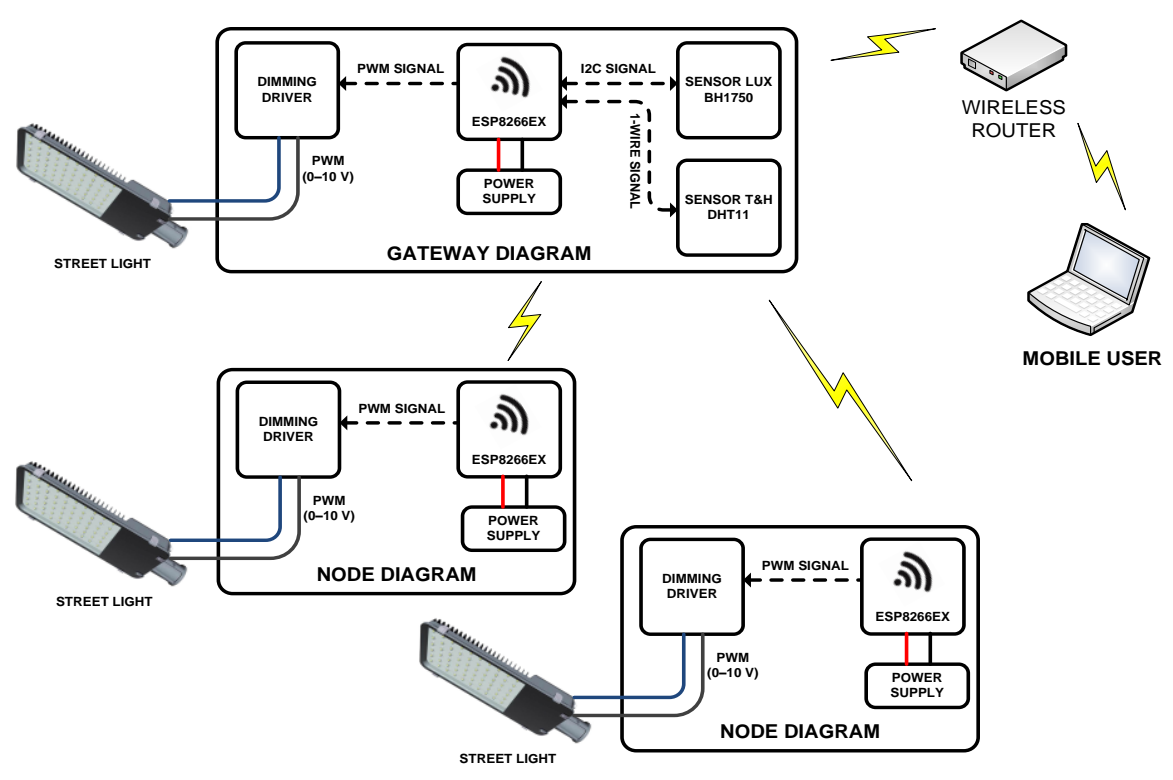

Fig. 1. Block diagram of control system 
The gateway is responsible for coordinating each node and it can send brightness packets to other nodes in the network through one or more wireless hops. Gateway has several services such as web services, light sensors (BH1750), temperature sensors, humidity (DHT11) and LEDs as end devices. Light sensors and humidity sensors have a function as a feedback system to determine the brightness value that will be sent to other nodes.

The BH1750 works by sensing the intensity of light in its environment. The output from the sensor is in Lux (Lx) that will be calculated to determine the optimal light intensity for saving energy. Whereas the DHT11 is used to detect temperature and humidity in environmental detection as previously elaborated in [3]. While node system consists of NodeMCU and LED. In this work, we used one LED module (type NL200D produced by $\mathrm{NoBi}^{\mathrm{TM}}$ ). Therefore, the electronic driver for dimmer control is needed. The driver output is $0-10 \mathrm{~V}_{\mathrm{DC}}$ depends on the PWM value as an input. In this work, we used five nodes: one node uses the real street light (LED module), and four nodes employ 3 Watt $p$ LED as the actual visualization of street lights. The hardware setup is visualized in Fig. 2.

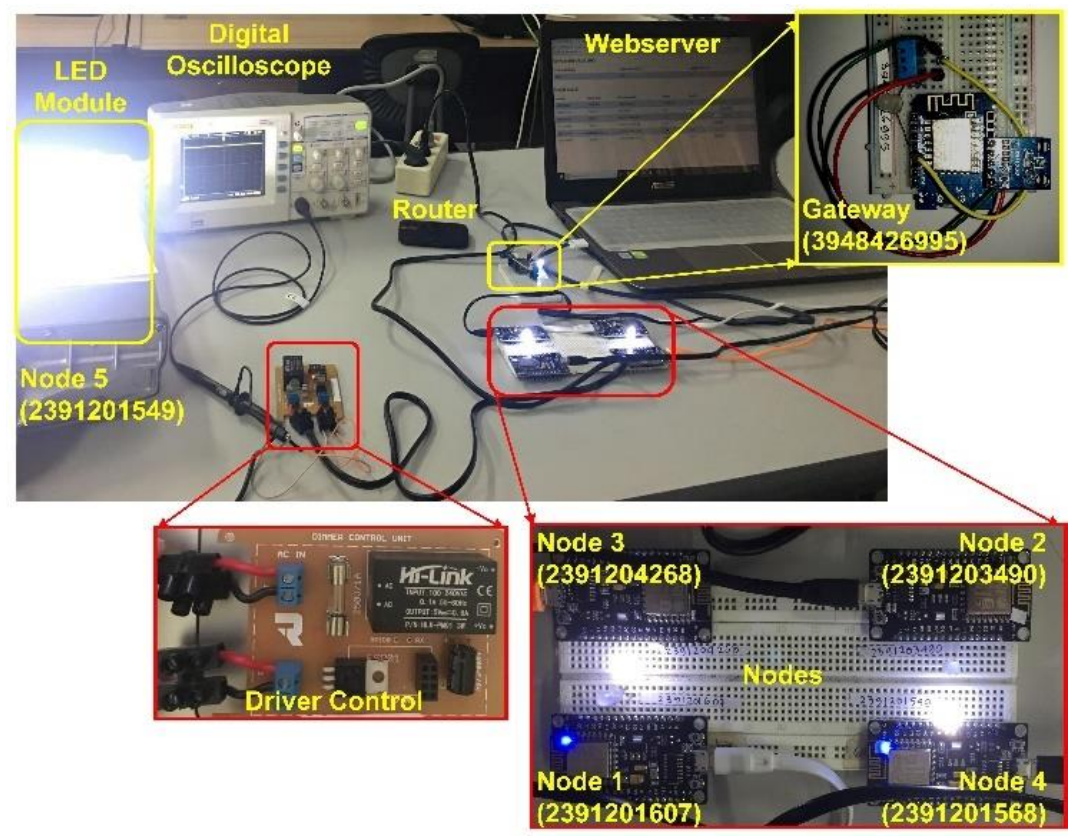

Fig. 2. System Architecture

The second part is software that could be categorized into two components, i.e., firmware and web server. The firmware part refers to Mesh network design. Besides the mesh network connecting function, the firmware has roles in transmitting and receiving a packet of nodes. In this work, we design Mesh networks as defined by ESP-Mesh, which has several features as following 1) Messages between different nodes are sent in JSON format because it makes the code and the messages human 
readable and easy to understand. It can be integrated into various programming languages, web applications, and other apps; 2) Single message and broadcast message are possible; 3) Accurate time synchronization, it means that all nodes share the same clock with a precision; 4) Mesh autoconfigure, it means that node can be disconnected at any moment so new node is integrated automatically; and 5) Routing message will be transmitted through hop from the closest node.

The designed Web server for smart street lighting system has four main features, i.e., 1) it can display the sensor data which is integrated into gateways such as light sensor, temperature, and humidity sensor; 2) display the information about mesh routing table from each LED streetlights. In addition, it displays information of PWM

level in a Mesh network; 3) ON/OFF feature for single or broadcast nodes which connected to Mesh networks, and 4) dimming features for single or broadcast node in a Mesh network.

\section{$3 \quad$ Results and Analysis}

After the hardware and software are integrated carefully as in Fig. 2, we first test the system functionally by sending the command ON/OFF to the LED module through a web server as reported in [2]. Once the test was successfully done, later we test the Mesh connection in which the experimental setup is depicted in Fig. 3. Moreover, we also observe web server performance in displaying the sensor information and Mesh table.

Based on the test result, the Mesh table can show the Mesh network routing as shown in Fig. 4 where node 3948426995 acts as a gateway (HOST GW). Node 2391201568 (Node 4) and 2391201607 (Node 1) are directly connected to the gateway. Node 1 has two sub connections and will be an access point for the next sub connection. Meanwhile, Node 4 in this table only has one sub connection. The node sequence shows the order of Mesh network connection that is connected directly to the gateway. Node 2391203490 (Node 2) as the first sub receive the message from Node 1. Node 2391204268 (Node 3) as the second sub receive a message from Node 2 as the first sub. Node 2391201549 (Node 5) as an NL200D LED module receive the message from 2391201568 (Node 4) that is directly connected to the gateway. After receiving a broadcast message, the node will process brightness value as PWM level and send an acknowledgment (ACK) to the gateway. 


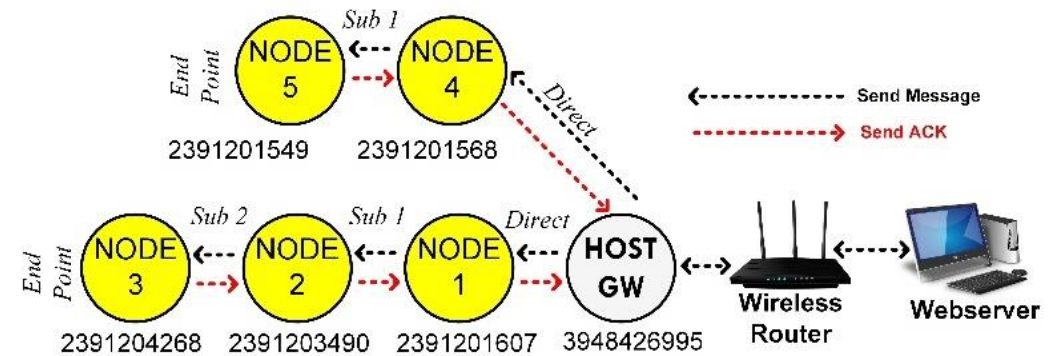

Fig. 3. ESP-Mesh Network Architecture for testing purpose

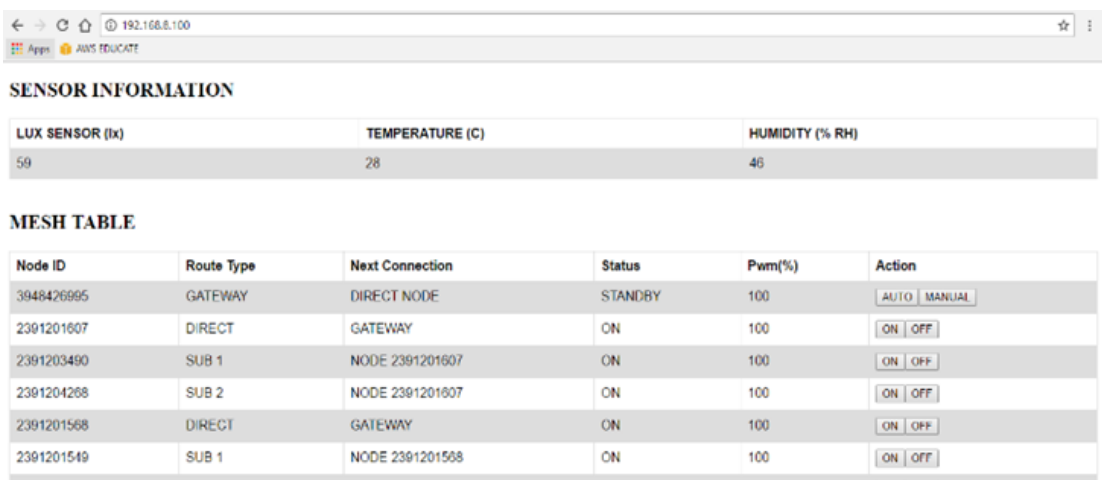

Fig. 4. Interface of web server (50 Lux, $28 \mathrm{oC}$, and $40 \% \mathrm{RH})$

\section{Conclusion}

An IoT-based Smart Street Lighting System using ESP8266 based on Mesh network has been developed and tested. In line with the functional test, we can conclude that the system works well as expected. Compared to [4] that use the analog sensor, our system is built with digitally-outputted sensors. Therefore, our system has a lower complexity. In future work, we address several scenarios for system testing related to Mesh connection.

\section{$5 \quad$ References}

[1] D. Jin, et al., "Smart street lighting system: A platform for innovative smart city applications and a new frontier for cyber-security," The Electricity J. Vol. 29(10), pp. 28-35, 2016. https://doi.org/10.1016/j.tej.2016.11.011

[2] S. Fuada, T. Adiono, and L. Siregar, "Development of Wireless Control System for Smart Street Lighting using ESP8266," Int. J. of Interactive Mobile Technologies (iJIM), Vol. 14(15), pp. 68-80, September 2020. https://doi.org/10.3991/ijim.v14i15.14081

[3] T. Adiono, M.Y. Fathany, S. Fuada, I.G. Purwanda, and S.F. Anindya, "A Portable Node of Humidity and Temperature Sensor for Indoor Environment Monitoring," Proc. of the 
3rd Int. Conf. on Intelligent Green Building and Smart Grid (IGBSG), pp. 1-5, https://doi. org/10.1109/igbsg.2018.8393575

[4] Y.H. Arzi and M. Rifki, "Development of Street Lights Controller Using WiFi Mesh Network," Proc. of Int. Conf. on Smart Cities, Automation \& Intellegent Computing Systems, 2017. https://doi.org/10.1109/icon-sonics.2017.8267830

\section{Authors}

Syifaul Fuada received a B.A. in Electrical Engineering Education from Universitas Negeri Malang (UM), Indonesia, and an M.Sc. in Electrical Engineering option Microelectronics from the School of Electrical Engineering and Informatics, Institut Teknologi Bandung (ITB), Indonesia. Now, he is with the Program Studi Sistem Telekomunikasi Universitas Pendidikan Indonesia (UPI) as a Lecturer. His research interests include analog circuit design and instrumentation, circuit simulation, engineering education, IoT, multimedia learning development and VLC.

Trio Adiono received a B.Eng. in electrical engineering and an M.Eng. in microelectronics from Institut Teknologi Bandung, Indonesia, in 1994 and 1996, respectively. He obtained his Ph.D. in VLSI Design from the Tokyo Institute of Technology, Japan, in 2002. He holds a Japanese Patent on a High-Quality Video Compression System. He is now a Full professor and a senior lecturer at the School of Electrical Engineering and Informatics, and formerly serves as the Head of the University Center of Excellence on Microelectronics, Institut Teknologi Bandung. His research interests include VLSI design, signal and image processing, VLC, smart cards, and electronics solution design and integration. tadiono@stei.itb.ac.id

Lindawani Siregar received a B.A. in Electrical Engineering from Universitas Pendidikan Indonesia, Indonesia, in 2015 and M.Sc. in Electrical Engineering option Microelectronics from the School of Electrical Engineering and Informatics, Institut Teknologi Bandung (ITB), Indonesia, in 2018. His research interests include VLSI, Robotics and Artificial Intelligence, and Internet of Things. The author can be contacted at Lindawanisiragar@gmail.com. She is with the Teaching Factory of Manufacturing Electronics, Politeknik Negeri Batam, Batam, Indonesia.

Article submitted 2021-03-24. Resubmitted 2021-04-18. Final acceptance 2021-04-19. Final version published as submitted by the authors. 